\title{
LYAPUNOV FUNCTION BASED CRITERIA FOR SHIP ROLLING IN RANDOM BEAM SEAS
}

\author{
Erdem Üçer \\ Istanbul Technical University, Faculty of Naval Architecture and Ocean Engineering, Turkey
}

\begin{abstract}
The aim of this study is to present a Lyapunov function which can be used to derive an intact stability criterion for a ship in random beam seas. First, the mathematical model of the rolling motion of ships in random beam seas is introduced. The random wave excitation is described by a spectrum which is depended on the wave energy spectrum and the amplitude of the moment of roll. This spectrum is generated by a second order linear filter. Second, the methodology of creating a Lyapunov function is explained briefly. Then, there is outlined the way by which Lyapunov function can be used as the intact stability criterion for a ship. The proposed criterion is derived by considering the weather criteria for German naval vessels. Finally, the coherence of the boundary of safe basin obtained by Lyapunov function with the numerical results obtained by Euler-Maruyama Method is presented. From the results it can be deduced that the Lyapunov function can be used to define an intact stability criterion.
\end{abstract}

Keywords: random beam sea, wave energy spectrum, Lyapunov function, intact stability criterion

\section{INTRODUCTION}

Modelling the dynamic behaviour of ships and offshore structures in their real working environment such as random seas and winds have always been a popular study subject since 1960s [3].

The earliest milestones on the investigation of ship rolling in random seas are the studies of Haddara [11], Odabasi [21] and Roberts [24].

Lyapunov Direct Method or Lyapunov functions [18, 25] are used since 1970 s to determine the conditions of stability against capsizing of ships. The studies of Odabasi [21], Ozkan [22] and Caldeira-Sariava [4] are the earliest examples of the usage of Lyapunov functions to investigate the rolling motions of ships. The more recent studies are the studies of Yilmaz [29] and Ucer [28].

The form parameters of fishing ships are analyzed by Y1lmaz [29] to establish a practical stability criterion in preliminary design stage.
In the study of Ucer [28], the transverse stability of BSRA trawlers are analyzed by using both numerical and analytical safe basin concepts and it is also demonstrated how the concept of safe basin can be utilized for the assessment of the stability of trawlers in regular beam seas.

The dynamic behaviour of elastic ocean structures of single degree of freedom is treated by an analytical approach based on the stochastic averaging of the energy envelope according to Moshchuk et al. [20]. The system is considered to be subject to a narrow-band random process modelled as the output of shaping filter. Three different shaping filters (first, second and fourth order) possessing Pierson-Moskowitz spectrum are employed to model Gaussian random sea waves.

The large-amplitude rolling and capsize dynamics of ships in random beam seas are investigated by using a nonlinear single-degree-of-freedom model by Jiang et al. [13]. In their work a criterion of capsizing is derived by using Melnikov function and phase-space transport techniques. 
The general non-linear model of parametric excited roll motions in head or following random seas is derived in the study of Dostal and Kreuzer [9]. The irregular waves are modelled in terms of a continuous time autoregressive moving average process. The resulting model of stochastic differential equations is investigated numerically by local statistical linearization.

An analytical criterion is provided by Dostal et al. [10] for ship and sea state parameters, which indicates the large roll amplitudes or capsizing and determines the mean time to these events.

The subject of this study, the rolling motion of a ship in random beam seas is recently investigated by Chai et al. [5-8].

The stochastic roll response and reliability of a ship in random beam seas is studied by using a four-dimensional (4D) path integration (PI) approach in the studies of Chai et al. [5-8] where a 4D Markov dynamic system is established by combining the single-degree-of freedom model used to represent the ship rolling behaviour in random beam seas with a second-order linear filter used to approximate the stationary roll excitation moment.

In this study, firstly the roll motion in beam seas is represented by the mathematical model derived by Chai et al. [5-8]. Secondly, the methodology of constructing a Lyapunov function of randomly exerted system is outlined. Then, it is presented how that Lyapunov function can be used as a tool for intact stability criterion similar to the weather criteria for German naval vessels [2]. Finally, the coherence of the boundary of safe basin of the ship, obtained by Lyapunov function, with the numerically determined safe basin is presented for two ships and three sea states.

\section{MATHEMATICAL MODEL}

While establishing the mathematical model, the couplings between the roll motion and other modes of ship motion are ignored to make the equation of roll motion simpler [5-9]. This assumption is based on the idea that roll motion has a greater influence on the ship stability in beam seas rather than the other modes of ship motion. Another reason for this simplification are the difficulties encountered when the complete hydrodynamic forces are accurately determined [15]. Although the coupling between the roll and sway motions is strong, it is possible to reduce one DOF by defining a virtual roll centre as indicated in the studies of Jiang [14], Hutchison [12] and Balcer [1].

The single degree of freedom (SDOF) roll motion equation in random beam seas can be represented by the equation (1) $[5-8]$.

$$
\begin{gathered}
I(\tilde{\omega}) \ddot{\emptyset}(t)+B_{44}(\widetilde{\omega}) \dot{\varnothing}(t)+B_{44 q}(\widetilde{\omega}) \dot{\varnothing}(t)|\varnothing(t)| \\
+\Delta G Z(\varnothing)=M(t)
\end{gathered}
$$

where $\phi$ is the rolling angle with respect to calm sea surface (rad), roll angular velocity ( $\mathrm{rad} / \mathrm{s})$, I denotes the virtual mass moment of inertia including the added mass moment in roll, $B_{44}(\widetilde{\omega})$ and $B_{44 q}(\widetilde{\omega})$ are the linear and quadratic damping coefficients, respectively, $\Delta$ is the displacement of the ship, $\omega$ is the wave circular frequency, $G Z$ is the righting arm as a function of the roll angle which can be defined by a single cubic polynomial and $M(t)$ is the external random wave excitation moment described by the spectrum $S_{\mathrm{mm}}(\omega)$. The excitation moment spectrum is related to the wave energy spectrum by the relationship shown in Eq. (2).

$$
S_{\mathrm{mm}}(\omega)=\left|F_{\mathrm{roll}}(\omega)\right| S_{\xi \xi}(\omega)
$$

where $\left|F_{\text {roll }}(\omega)\right|$ represents amplitude of the moment of the roll motion per unit wave height at frequency $\omega$ and $S_{\xi \xi}(\omega)$ is the wave energy spectrum [5-9].

The equation (3) is the spectrum of the relative wave excitation moment $S_{\mathrm{mm}}(\omega)$ generated by a second-order linear filter shown in equation (4) and (5) [5-9].

$$
\begin{gathered}
S_{\mathrm{mm}}(\omega)=\frac{1}{2 \pi} \frac{\gamma^{2}}{\left(\alpha-\omega^{2}\right)^{2}+(\beta \omega)^{2}} \\
d x_{3}=\left(x_{4}-\beta x_{3}\right) d t+\gamma d W \\
d x_{4}=-\alpha x_{3} d t
\end{gathered}
$$

where $x_{3}$ and $x_{4}$ are the state variables in filter equation with $x_{3}$ representing the output term $\mathrm{m}(t), d W(t)=W(t+d t)-W(t)$ represents an infinitesimal increment of a standard Wiener process, $\alpha, \beta$ and $\gamma$ are the parameters of the linear filter [5-9].

With the aid of linear filtering technique, the roll motion equation (1) is described by the following four dimensional state space equations (6-9) [5-8].

$$
\begin{gathered}
d x_{1}=x_{2} d t \\
d x_{2}=\left(-b_{44} x_{2}-b_{44 q} x_{2}\left|x_{2}\right|-c_{1} x_{1}\right. \\
\left.+c_{3} x_{1}^{3}+x_{3}\right) d t \\
d x_{3}=\left(x_{4}-\beta x_{3}\right) d t+\gamma d W \\
d x_{4}=-\alpha x_{3}
\end{gathered}
$$

Where $x_{1}$ is the roll angle $\phi(t), x_{2}$ is the roll angular velocity $x_{2}=\dot{\varnothing}(t), x_{3}$ is the ratio of the external random wave excitation moment and the virtual mass moment of inertia $x_{3}=M(t) / I$, the damping moment coefficients $b_{44}$ and $b_{44 q}$ are equal to $B_{44} / I$ and $B_{44 q} / I$, respectively, the righting arm coefficients $c_{1}$ and $c_{3}$ are equal to $\Delta G M / I$, and $-\Delta G M /\left(I \phi_{v}{ }^{2}\right)=c_{1} / \phi_{v}{ }^{2}$, respectively.

\section{LYAPUNOV FUNCTION OF RANDOM PROCESS}

Let the $d x=f(x, t) d t+\sigma(x, t) d z$ be the stochastic differential (Ito) equation.

In order to derive a Lyapunov function, $V(x)$, the following assumptions are made [16]: 
- $V(x)$ should be a non-negative and continuous function, satisfying $V(0)=0, V(x)>0$ at $x \neq 0$

- $V(x)$ should have continuous first partial derivatives in $Q_{\mathrm{m}} \equiv\{\mathrm{x}: V(x)<\mathrm{m}\} \mathrm{m}<\infty$.

When the derivative of Lyapunov function $L V(x)$ is smaller and equal to a continuous positive function $k(x)$, the system is stable.

The differential generator of the random process is given by the following equation $[16,25]$ :

$$
L=\sum_{i} f_{i}(x, t) \frac{\partial}{\partial x_{i}}+\frac{1}{2} \sum_{i, j} S_{i, j}(x, t) \frac{\partial^{2}}{\partial_{x_{i}} \partial_{x_{j}}}
$$

where $S(x)=\left\{S_{i j}(x)\right\}=\sigma^{\prime}(x) \sigma(x)$

\section{CONSTRUCTION OF LYAPUNOV FUNCTION OF RANDOM ROLL MOTION OF A SHIP}

In this section the determination of analytical safe basin for forced non-linear rolling motion by using Lyapunov function is presented. Firstly, a positive analytical function is determined [4, 21-22, 25, 28-29]. Secondly, the derivative of this analytical function is obtained. When the derivative of this analytical function is negative, the ship is assumed to be stable [28].

The positive analytical function, Lyapunov function of the equation system (6-9), is assumed as the expression given in equation (11).

$$
V=\left(1+k_{3} x_{3}^{2}+k_{4} x_{4}^{2}\right) \frac{x_{2}^{2}}{2}+k_{1} \frac{x_{1}^{2}}{2}
$$

The above given function is non-negative continuous and satisfying $V(0)=0$ and $V(x)>0$ at $x \neq 0$ and also has continuous first partial derivatives.

By using the differential generator (10), the derivative of the Lyapunov function is found as:

$$
\begin{gathered}
L V=\left(1+k_{3} x_{3}^{2}+k_{4} x_{4}^{2}\right)\left(-b_{44} x_{2}^{2}-b_{44 q}\left|x_{2}\right| x_{2}^{2}-c_{1} x_{1} x_{2}\right. \\
\left.+c_{3} x_{1}^{3} x_{2}+x_{3} x_{2}\right)+k_{1} x_{1} x_{2}+k_{3} x_{3} x_{4} x_{2}^{2}-k_{3} \beta x_{2}^{2} x_{3}^{2} \\
+\frac{\gamma^{2}}{2} k_{3} x_{2}^{2}-\alpha x_{3} x_{4} k_{4} x_{2}^{2}
\end{gathered}
$$

When the coefficient $k_{3}$ is assumed equal to $\alpha k_{4}$, the equation (12) is simplified and the following expression is obtained:

$$
\begin{aligned}
L V= & \left(1+k_{3} x_{3}^{2}+k_{4} x_{4}^{2}\right)\left(-b_{44} x_{2}^{2}-b_{44 q}\left|x_{2}\right| x_{2}^{2}-c_{1} x_{1} x_{2}\right. \\
& \left.+c_{3} x_{1}^{3} x_{2}+x_{3} x_{2}\right)+k_{1} x_{1} x_{2}-k_{3} x_{2}^{2}\left(\beta x_{3}^{2}-\frac{\gamma^{2}}{2}\right)
\end{aligned}
$$

Let $1+k_{3} x_{3}^{2}+k_{4} x_{4}^{2}$ be smaller than any positive real number $K$ smaller than infinity. On this assumption and regrouping the parentheses the equation (13) turns into the equation (14). When the expression given by the equation (14) is smaller and equal to zero, the system is stable.

$$
\begin{gathered}
L V=K\left(-x_{2}^{2}\left(b_{44}+b_{44 q}\left|x_{2}\right|\right)-x_{2}\left(c_{1} x_{1}-c_{3} x_{1}^{3}-x_{3}\right)\right) \\
+k_{1} x_{1} x_{2}-k_{3} x_{2}^{2}\left(\beta x_{3}^{2}-\frac{\gamma^{2}}{2}\right) \leq 0
\end{gathered}
$$

When the both sides of the above given equation is divided by $K$ positive constant and after regrouping the parentheses, the following expression is obtained:

$$
\begin{gathered}
-x_{2}^{2}\left(b_{44}+b_{44 q}\left|x_{2}\right|\right)-x_{2}\left(\left(c_{1}-k_{1}^{*}\right) x_{1}-c_{3} x_{1}^{3}-x_{3}\right) \\
-k_{3}^{*} x_{2}^{2}\left(\beta x_{3}^{2}-\frac{\gamma^{2}}{2}\right) \leq 0
\end{gathered}
$$

where $k_{1}^{*}=k_{1} / K$ and $k_{3}^{*}=k_{3} / K$

Let's assume $x_{3 \mathrm{~m}}$ is the greatest value of $x_{3}$ and put into the equation (15) in the place of $x_{3}$. Then, the equation (15) turns into the equation (16).

$$
\begin{gathered}
-x_{2}^{2}\left(b_{44}+b_{44 q}\left|x_{2}\right|\right)-x_{2}\left(\left(c_{1}-k_{1}^{*}\right) x_{1}-c_{3} x_{1}^{3}-x_{3 \mathrm{~m}}\right) \\
-k_{3}^{*} x_{2}^{2}\left(\beta x_{3 \mathrm{~m}}^{2}-\frac{\gamma^{2}}{2}\right)=0
\end{gathered}
$$

After regrouping parentheses and dividing both sides of the equation (16) by $x_{2}$, the equation (17) is obtained.

$$
\begin{gathered}
x_{2}\left(b_{44}+b_{44 q}\left|x_{2}\right|+k_{3}^{*}\left(\beta x_{3 \mathrm{~m}}^{2}-\frac{\gamma^{2}}{2}\right)\right) \\
=\left[x_{3 \mathrm{~m}}-\left(\left(c_{1}-k_{1}^{*}\right) x_{1}-c_{3} x_{1}^{3}\right)\right]
\end{gathered}
$$

When the above given condition is satisfied, the ship can be assumed stable. Hence, the two unknown parameters of the equation (17), $k_{1}^{*}$ and $k_{3}^{*}$, should be determined. The determination of the parameters is explained in the next section.

\section{LYAPUNOV FUNCTION BASED CRITERIA}

The graphical representation of the right hand side of the equation (17) is shown in Fig. 1.

In the figure, $x_{1 s t}\left(\phi_{s t}\right)$ is the static heel angle which is represented by the intersection point of the line of maximum value of the external excitation $x_{3 \mathrm{~m}}$ and the modified restoring arm curve $\left(g z^{*}=\left(c_{1}-k_{1}^{*}\right) x_{1}-c_{3} x_{1}^{3}\right)$. According to the weather criteria for German naval vessels, $x_{1 \text { ref }}\left(\phi_{\text {ref }}\right)$, the reference angle and $h_{\text {res }}$, the residual arm between the restoring and the excitation moment are determined by means of the equation (18) or (19) [2].

$$
\begin{gathered}
\phi_{\text {ref }}=35^{\circ} \text { and } h_{\text {res }}=0.1 \mathrm{~m} \text { for } \phi_{s t} \leq 15^{\circ} \\
\phi_{\text {ref }}=2 \times \phi_{s t}+5^{\circ} \text { and } h_{\text {res }}=0.01 \times \phi_{s t}-0.05, \phi_{s t}>15^{\circ}
\end{gathered}
$$

where both $\phi_{s t}$ and $\phi_{\text {ref }}$ are expressed in degrees. 


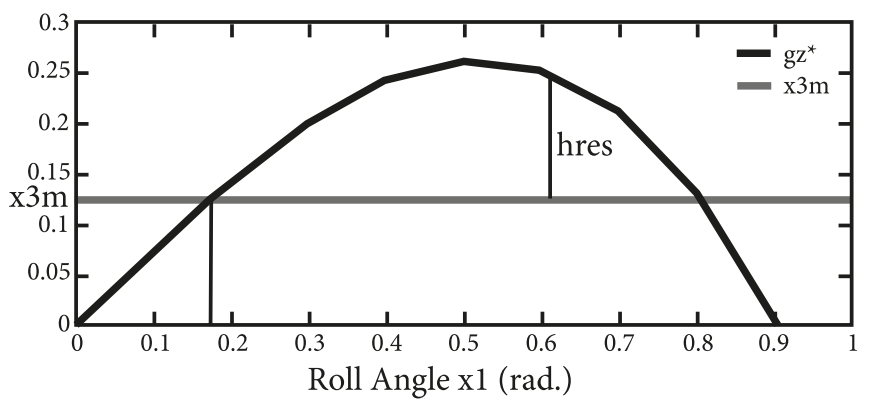

Fig. 1. Modified restoring arm curve with external excitation

The unknown parameters $k_{1}^{*}$ and $k_{3}^{*}$ are determined by the numerical solution of the system of the equations (20)-(25) which are derived by making the following assumptions:

- $x_{1 s t}$ is the intersection point of the modified $g z$ curve and the maximum external excitation lever $x_{3 \mathrm{~m}}$ determined by the equation (20).

- The roll angular velocity $x_{2}$ gets its highest value $\left(x_{2 \mathrm{~m}}\right)$ when the roll angle is zero. Then, the equation (21) is obtained by putting $x_{2 \mathrm{~m}}$ and 0 instead of $x_{2}$ and $x_{1}$, respectively, in the equation (17).

- It is assumed that the ship must have the half of the maximum roll angular velocity $\left(x_{2 \mathrm{~m}}\right)$ at the reference angle of heel $\left(x_{1 \text { ref }}\right)$. Then, the equation (22) is obtained by putting $\left(x_{2 \mathrm{~m}} / 2\right)$ and $x_{1 \mathrm{ref}}$ instead of $x_{2}$ and $x_{1}$, respectively, in the equation (17).

- In the equation (23), it is stated that the ship must have the residual $\operatorname{arm} h_{\text {res }}$ at the roll angle $x_{a}$. The value of $h_{\text {res }}$ is determined by the following condition:

$x_{1 s t} \leq 15^{\circ}$ then $h_{\text {res }}=0.01$

$x_{1 s t}>15^{\circ}$ then $h_{\text {res }}=0.01 \mathrm{x}_{1 s t}-0.05$.

- The equation (24) shows that the coefficient $k_{1}^{*}$ depends on $x_{2 \mathrm{~m}}$ and $x_{b}$ and is obtained by dividing the equation (11) by $K$ constant and assuming that the energy on the boundary is equal to $\left(x_{2 \mathrm{~m}}{ }^{2} / 2\right)$ and the width of safe basin is $x_{b}$.

- The width of the safe basin $\left(x_{b}\right)$ is assumed to be equal to the expression represented by the equation (25). When $x_{4}$ and $x_{1 s t}$ get higher values, the width of safe basin decreases.

$$
\begin{gathered}
\left(c_{1}-k_{1}^{*}\right) x_{1 s t}-c_{3} \mathrm{x}_{1 s t}^{3}-\mathrm{x}_{3 \mathrm{~m}}=0 \\
-x_{2 \mathrm{~m}}\left(b_{44}+b_{44 q}\left|x_{2 \mathrm{~m}}\right|\right)-x_{3 \mathrm{~m}} \\
-k_{3}^{*} x_{2 \mathrm{~m}}\left(\beta x_{3 \mathrm{~m}}^{2}-\frac{\gamma^{2}}{2}\right)=0 \\
\frac{x_{2 \mathrm{~m}}}{2}\left(b_{44}+b_{44 q} \mid \frac{x_{2 \mathrm{~m}}}{2}+k_{3}^{*}\left(\beta x_{3 \mathrm{~m}}^{2}-\frac{\gamma^{2}}{2}\right)\right) \\
-\left[x_{3 \mathrm{~m}}-\left(\left(c_{1}-k_{1}^{*}\right) x_{1 \mathrm{ref}}-c_{3} x_{1 \mathrm{ref}}^{3}\right)\right]=0 \\
\left(c_{1}-k_{1}^{*}\right) x_{\mathrm{a}}-c_{3} x_{\mathrm{a}}^{3}-x_{3 \mathrm{~m}}-h_{\mathrm{res}}=0 \\
k_{1}^{*}=\left(x_{2 \mathrm{~m}} / x_{b}\right)^{2} \\
x_{b}=0.8 x_{v}-x_{1 s t}-x_{a}
\end{gathered}
$$

here $x_{v}$ is the vanishing stability angle, the coefficients $k_{1}^{*}$ and $k_{3}^{*}$ should be positive.

The input values to the above equation system are the restoring and damping coefficients, second order linear filter parameters and the maximum external excitation value $x_{3 \mathrm{~m}}$. The output of the equation system is $x_{1 \mathrm{st}}, x_{2 \mathrm{~m}}, x_{a}$ and $k_{3}{ }^{*}$. It is also possible to easily obtain $x_{b}$ by putting the values of $x_{1 s t}$ and $x_{a}$ into the equation (25).

Whether the ship has a safe region or not can easily be understood by looking at the values $x_{2 \mathrm{~m}}$ and $x_{b}$.

\section{DATA FOR ROLLING MOTION EQUATION}

In this study, the data of a fishery research vessel [6] is used to test the criteria based on Lyapunov function. The main parameters of the ship model are given in Tab. 1.

Tab. 1. List of ship parameters

\begin{tabular}{|c|c|}
\hline$I$ & $5540 \times 10^{7} \mathrm{~kg} \mathrm{~m}^{2}$ \\
\hline$\Delta$ & $2017 \times 10^{7} \mathrm{~N}$ \\
\hline$b_{44}$ & $0.095 \mathrm{~s}^{-1}$ \\
\hline$b_{44 q}$ & 0.0519 \\
\hline$c_{1}$ & $1.153 \mathrm{~s}^{-2}$ \\
\hline$c_{3}$ & $0.915 \mathrm{~s}^{-2}$ \\
\hline$\omega_{0}$ & $1.074 \mathrm{rad} / \mathrm{s}$ \\
\hline$x_{v}$ & $1.1 \mathrm{rad}$ \\
\hline
\end{tabular}

The parameters $\alpha, \beta$ and $\gamma$ in the second order linear filter equation (4) and (5) are presented in Tab. 2 [6].

Tab. 2. List of second order linear filter parameters

\begin{tabular}{|c|c|c|c|c|c|}
\hline Sea States & $\mathrm{H}_{\mathrm{s}}(\mathrm{m})$ & $\mathrm{T}_{\mathrm{p}}(\mathrm{s})$ & $\alpha$ & $\beta$ & $\gamma$ \\
\hline Sea State 1 & 4.0 & 11.0 & 0.495 & 0.366 & 0.0432 \\
\hline Sea State 2 & 5.0 & 12.0 & 0.441 & 0.364 & 0.0498 \\
\hline Sea State 3 & 6.0 & 13.0 & 0.390 & 0.365 & 0.0555 \\
\hline
\end{tabular}

\section{RESULTS}

In this section, for three sea states [6], the safe basins of roll motion of the fishery vessel are obtained from both the numerical solutions of the equation system (6)-(9) and the equation system (20)-(25) created by means of Lyapunov Direct Method. Then, the safe basins of roll motion of the fishery vessel, obtained in different ways, are compared.

Firstly, the equation system (20)-(25) are numerically solved with different initial conditions of $x_{2 \mathrm{~m}}, x_{a}$ and $x_{3 \mathrm{~m}}$.

The output of the equation system (20)-(25) for the fishery vessel is presented for different initial conditions in Tab. 3-6 for Sea state 1 and Tab. 7-8 for Sea state 3. In each table, the highest values of $x_{2 \mathrm{~m}}$ and $x_{b}$ which gives the largest safe basin are marked bold. 
Tab. 3. The outputs for Sea state 1 with the initial

values of $x_{1 s t}=0.1, k_{3}=0.2, x_{a}=0.5$ and $x_{3 m}=\gamma /(2 \alpha \sqrt{2 \beta})$

\begin{tabular}{|c|c|c|c|c|}
\hline $\begin{array}{c}\text { Initial } \\
x_{2 \mathrm{~m}}\end{array}$ & $\begin{array}{c}x_{1 s t} \\
(\mathrm{rad})\end{array}$ & $\begin{array}{c}x_{2 \mathrm{~m}} \\
(\mathrm{rad} / \mathrm{s})\end{array}$ & $\begin{array}{c}x_{a} \\
(\mathrm{rad})\end{array}$ & $\begin{array}{c}x_{b} \\
(\mathrm{rad})\end{array}$ \\
\hline 0.1 & 0.126 & 0.301 & 0.397 & 0.357 \\
\hline 0.2 & 0.119 & 0.308 & 0.397 & 0.364 \\
\hline 0.3 & 0.114 & 0.312 & 0.397 & 0.369 \\
\hline 0.4 & 0.104 & 0.322 & 0.396 & 0.380 \\
\hline 0.5 & 0.119 & 0.311 & 0.395 & 0.366 \\
\hline $\mathbf{0 . 6}$ & $\mathbf{0 . 1 0 8}$ & $\mathbf{0 . 3 2 6}$ & $\mathbf{0 . 3 8 8}$ & $\mathbf{0 . 3 8 4}$ \\
\hline 0.7 & 0.106 & 0.323 & 0.394 & 0.380 \\
\hline 0.8 & 0.122 & 0.311 & 0.392 & 0.366 \\
\hline 0.9 & 0.121 & 0.312 & 0.393 & 0.366 \\
\hline 1.0 & 0.114 & 0.318 & 0.394 & 0.373 \\
\hline
\end{tabular}

Tab. 4. The outputs for Sea state 1 with the initial

values of $x_{1 s t}=0.1, k_{3}=0.2, x_{a}=0.75$ and $x_{3 m}=\gamma /(2 \alpha \sqrt{2 \beta})$

\begin{tabular}{|c|c|c|c|c|}
\hline $\begin{array}{c}\text { Initial } \\
x_{2 \mathrm{~m}}\end{array}$ & $\begin{array}{c}x_{1 s t} \\
(\mathrm{rad})\end{array}$ & $\begin{array}{c}x_{2 \mathrm{~m}} \\
(\mathrm{rad} / \mathrm{s})\end{array}$ & $\begin{array}{c}x_{a} \\
(\mathrm{rad})\end{array}$ & $\begin{array}{c}x_{b} \\
(\mathrm{rad})\end{array}$ \\
\hline 0.1 & 0.131 & 0.304 & 0.393 & 0.356 \\
\hline $\mathbf{0 . 2}$ & $\mathbf{0 . 1 0 5}$ & $\mathbf{0 . 3 2 3}$ & $\mathbf{0 . 3 9 4}$ & $\mathbf{0 . 3 8 1}$ \\
\hline 0.3 & 0.108 & 0.320 & 0.395 & 0.377 \\
\hline 0.4 & 0.114 & 0.312 & 0.397 & 0.369 \\
\hline 0.5 & 0.121 & 0.309 & 0.395 & 0.364 \\
\hline 0.6 & 0.119 & 0.310 & 0.395 & 0.366 \\
\hline 0.7 & 0.122 & 0.308 & 0.394 & 0.363 \\
\hline 0.8 & 0.123 & 0.308 & 0.394 & 0.363 \\
\hline 0.9 & 0.123 & 0.309 & 0.394 & 0.364 \\
\hline 1.0 & 0.125 & 0.303 & 0.399 & 0.356 \\
\hline
\end{tabular}

Tab. 5. The outputs for Sea state 1 with the initial values of $x_{1 s t}=0.1, k_{3}=0.2, x_{a}=0.5$ and $x_{3 m}=\gamma /(\alpha \sqrt{2 \beta})$

\begin{tabular}{|c|c|c|c|c|}
\hline $\begin{array}{c}\text { Initial } \\
x_{2 \mathrm{~m}}\end{array}$ & $\begin{array}{c}x_{1 s t} \\
(\mathrm{rad})\end{array}$ & $\begin{array}{c}x_{2 \mathrm{~m}} \\
(\mathrm{rad} / \mathrm{s})\end{array}$ & $\begin{array}{c}x_{a} \\
(\mathrm{rad})\end{array}$ & $\begin{array}{c}x_{b} \\
(\mathrm{rad})\end{array}$ \\
\hline 0.1 & 0.178 & 0.203 & 0.443 & 0.259 \\
\hline 0.2 & 0.182 & 0.203 & 0.441 & 0.257 \\
\hline 0.3 & 0.185 & 0.206 & 0.434 & 0.261 \\
\hline $\mathbf{0 . 4}$ & $\mathbf{0 . 1 7 1}$ & $\mathbf{0 . 2 1 4}$ & $\mathbf{0 . 4 3 7}$ & $\mathbf{0 . 2 7 2}$ \\
\hline 0.5 & 0.182 & 0.209 & 0.434 & 0.264 \\
\hline 0.6 & 0.174 & 0.213 & 0.436 & 0.270 \\
\hline 0.7 & 0.182 & 0.210 & 0.433 & 0.264 \\
\hline 0.8 & 0.180 & 0.210 & 0.436 & 0.264 \\
\hline 0.9 & 0.193 & 0.206 & 0.429 & 0.258 \\
\hline 1.0 & 0.193 & 0.201 & 0.434 & 0.253 \\
\hline
\end{tabular}

Tab. 6. The outputs for Sea state 1 with the initial values of $x_{1 s t}=0.1, k_{3}=0.2, x_{a}=0.75$ and $x_{3 m}=\gamma /(\alpha \sqrt{2 \beta})$

\begin{tabular}{|c|c|c|c|c|}
\hline $\begin{array}{c}\text { Initial } \\
x_{2 \mathrm{~m}}\end{array}$ & $\begin{array}{c}x_{1 \mathrm{st}} \\
(\mathrm{rad})\end{array}$ & $\begin{array}{c}x_{2 \mathrm{~m}} \\
(\mathrm{rad} / \mathrm{s})\end{array}$ & $\begin{array}{c}x_{a} \\
(\mathrm{rad})\end{array}$ & $\begin{array}{c}x_{b} \\
(\mathrm{rad})\end{array}$ \\
\hline 0.1 & 0.182 & 0.210 & 0.433 & 0.265 \\
\hline 0.2 & 0.191 & 0.207 & 0.431 & 0.259 \\
\hline 0.3 & 0.191 & 0.204 & 0.432 & 0.257 \\
\hline 0.4 & 0.168 & 0.219 & 0.436 & 0.276 \\
\hline 0.5 & 0.176 & 0.210 & 0.439 & 0.265 \\
\hline 0.6 & 0.173 & 0.211 & 0.440 & 0.266 \\
\hline 0.7 & 0.178 & 0.212 & 0.435 & 0.267 \\
\hline 0.8 & 0.199 & 0.198 & 0.433 & 0.248 \\
\hline $\mathbf{0 . 9}$ & $\mathbf{0 . 1 6 1}$ & $\mathbf{0 . 2 2 9}$ & $\mathbf{0 . 4 3 1}$ & $\mathbf{0 . 2 8 8}$ \\
\hline 1.0 & 0.193 & 0.204 & 0.431 & 0.256 \\
\hline
\end{tabular}

Tab. 7. The outputs for Sea state 3 with the initial values of $x_{1 s t}=0.1, k_{3}=0.2, x_{a}=0.5$ and $x_{3 m}=\gamma /(2 \alpha \sqrt{2 \beta})$

\begin{tabular}{|c|c|c|c|c|}
\hline $\begin{array}{c}\text { Initial } \\
x_{2 \mathrm{~m}}\end{array}$ & $\begin{array}{c}x_{1 s t} \\
(\mathrm{rad})\end{array}$ & $\begin{array}{c}x_{2 \mathrm{~m}} \\
(\mathrm{rad} / \mathrm{s})\end{array}$ & $\begin{array}{c}x_{a} \\
(\mathrm{rad})\end{array}$ & $\begin{array}{c}x_{b} \\
(\mathrm{rad})\end{array}$ \\
\hline 0.1 & 0.165 & 0.234 & 0.425 & 0.289 \\
\hline 0.2 & 0.169 & 0.233 & 0.423 & 0.288 \\
\hline 0.3 & 0.162 & 0.236 & 0.426 & 0.292 \\
\hline 0.4 & 0.158 & 0.243 & 0.423 & 0.299 \\
\hline 0.5 & 0.155 & 0.246 & 0.423 & 0.302 \\
\hline $\mathbf{0 . 6}$ & $\mathbf{0 . 1 5 4}$ & $\mathbf{0 . 2 4 7}$ & $\mathbf{0 . 4 2 2}$ & $\mathbf{0 . 3 0 4}$ \\
\hline 0.7 & 0.167 & 0.238 & 0.421 & 0.292 \\
\hline 0.8 & 0.174 & 0.235 & 0.419 & 0.287 \\
\hline 0.9 & 0.173 & 0.235 & 0.419 & 0.288 \\
\hline 1.0 & 0.173 & 0.235 & 0.419 & 0.288 \\
\hline
\end{tabular}

Tab. 8. The outputs for Sea state 3 with the initial values of $x_{1 s t}=0.1, k_{3}=0.2, x_{a}=0.75$ and $x_{3 m}=\gamma /(2 \alpha \sqrt{2 \beta})$

\begin{tabular}{|c|c|c|c|c|}
\hline $\begin{array}{c}\text { Initial } \\
x_{2 \mathrm{~m}}\end{array}$ & $\begin{array}{c}x_{1 s t} \\
(\mathrm{rad})\end{array}$ & $\begin{array}{c}x_{2 \mathrm{~m}} \\
(\mathrm{rad} / \mathrm{s})\end{array}$ & $\begin{array}{c}x_{a} \\
(\mathrm{rad})\end{array}$ & $\begin{array}{c}x_{b} \\
(\mathrm{rad})\end{array}$ \\
\hline 0.1 & 0.177 & 0.234 & 0.417 & 0.285 \\
\hline 0.2 & 0.200 & 0.218 & 0.415 & 0.265 \\
\hline 0.3 & 0.170 & 0.238 & 0.419 & 0.292 \\
\hline 0.4 & 0.169 & 0.238 & 0.420 & 0.292 \\
\hline 0.5 & $\mathbf{0 . 1 5 2}$ & $\mathbf{0 . 2 5 1}$ & $\mathbf{0 . 4 2 0}$ & $\mathbf{0 . 3 0 8}$ \\
\hline 0.6 & 0.157 & 0.244 & 0.423 & 0.301 \\
\hline 0.7 & 0.176 & 0.233 & 0.419 & 0.285 \\
\hline 0.8 & 0.177 & 0.232 & 0.419 & 0.285 \\
\hline 0.9 & 0.167 & 0.239 & 0.420 & 0.293 \\
\hline 1.0 & 0.158 & 0.246 & 0.420 & 0.302 \\
\hline
\end{tabular}


The highest values of $x_{2 \mathrm{~m}}$ and $x_{b}$ are presented for different maximum excitation levers $\left(x_{3 \mathrm{~m}}\right)$ in Tab. 9-14 for Sea state 1, Sea state 2 and 3, respectively. As can be seen from the tables, the percentage difference between the highest values of $x_{2 \mathrm{~m}}$ and $x_{b}$ obtained by using the initial value of $x_{a}=0.5$ and $x_{a}=0.75$ is less than 2 . The solution of the equation system shows the same characteristics for different initial conditions.

The size of the safe basins is highly dependent on the selection of the value of $x_{3 \mathrm{~m}}$ which is the greatest value of $x_{3}$ (the ratio of the external random wave excitation moment and the virtual mass moment of inertia). Selecting small value of $x_{3 \mathrm{~m}}$ results in not representing of sea state and also that the safe basin is greater than expected whereas selecting bigger value of $x_{3 \mathrm{~m}}$ causes safe basin smaller than expected.

While comparing the safe basins obtained by the numerical solutions of the equation system (3)-(6) and equation system (19)-(25), the value of $x_{3 \mathrm{~m}}$ is assumed equal to $\gamma /(2 \alpha \sqrt{2 \beta})$. The values of $x_{2 \mathrm{~m}}$ and $x_{b}$ used for obtaining the safe basins are presented in Tab. 15.

Tab. 9. The highest values of $x_{2 m}$ and $x_{b}$ for Sea state 1 with the initial values of $x_{1 s t}=0.1, k_{3}=0.2$ and $x_{a}=0.5$

\begin{tabular}{|c|c|c|c|c|}
\hline$x_{3 \mathrm{~m}}$ & $\begin{array}{c}x_{1 s t} \\
(\mathrm{rad})\end{array}$ & $\begin{array}{c}x_{2 \mathrm{~m}} \\
(\mathrm{rad} / \mathrm{s})\end{array}$ & $\begin{array}{c}x_{a} \\
(\mathrm{rad})\end{array}$ & $\begin{array}{c}x_{b} \\
(\mathrm{rad})\end{array}$ \\
\hline$\gamma /(3 \alpha \sqrt{2 \beta})$ & 0.062 & 0.383 & 0.377 & 0.441 \\
\hline$\gamma /(2 \alpha \sqrt{2 \beta})$ & 0.108 & 0.326 & 0.388 & 0.384 \\
\hline$\gamma /(\alpha \sqrt{2 \beta})$ & 0.171 & 0.214 & 0.437 & 0.272 \\
\hline $3 \gamma /(2 \alpha \sqrt{2 \beta})$ & 0.199 & 0.156 & 0.467 & 0.213 \\
\hline
\end{tabular}

Tab. 10. The highest values of $x_{2 m}$ and $x_{b}$ for Sea state 1 with the initial values of $x_{1 s t}=0.1, k_{3}=0.2$ and $x_{a}=0.75$

\begin{tabular}{|c|c|c|c|c|}
\hline$x_{3 \mathrm{~m}}$ & $\begin{array}{c}x_{1 s t} \\
(\mathrm{rad})\end{array}$ & $\begin{array}{c}x_{2 \mathrm{~m}} \\
(\mathrm{rad} / \mathrm{s})\end{array}$ & $\begin{array}{c}x_{a} \\
(\mathrm{rad})\end{array}$ & $\begin{array}{c}x_{b} \\
(\mathrm{rad})\end{array}$ \\
\hline$\gamma /(3 \alpha \sqrt{2 \beta})$ & 0.064 & 0.375 & 0.382 & 0.434 \\
\hline$\gamma /(2 \alpha \sqrt{2 \beta})$ & 0.105 & 0.323 & 0.394 & 0.381 \\
\hline$\gamma /(\alpha \sqrt{2 \beta})$ & 0.161 & 0.229 & 0.431 & 0.288 \\
\hline $3 \gamma /(2 \alpha \sqrt{2 \beta})$ & 0.208 & 0.145 & 0.474 & 0.198 \\
\hline
\end{tabular}

Tab. 11. The highest values of $x_{2 m}$ and $x_{b}$ for Sea state 2 with the initial values of $x_{1 s t}=0.1, k_{3}=0.2$ and $x_{a}=0.5$

\begin{tabular}{|c|c|c|c|c|}
\hline$x_{3 \mathrm{~m}}$ & $\begin{array}{c}x_{1 s t} \\
(\mathrm{rad})\end{array}$ & $\begin{array}{c}x_{2 \mathrm{~m}} \\
(\mathrm{rad} / \mathrm{s})\end{array}$ & $\begin{array}{c}x_{a} \\
(\mathrm{rad})\end{array}$ & $\begin{array}{c}x_{b} \\
(\mathrm{rad})\end{array}$ \\
\hline$\gamma /(3 \alpha \sqrt{ } 2 \beta)$ & 0.083 & 0.355 & 0.383 & 0.414 \\
\hline$\gamma /(2 \alpha \sqrt{ } 2 \beta)$ & 0.115 & 0.291 & 0.413 & 0.352 \\
\hline$\gamma /(\alpha \sqrt{ } 2 \beta)$ & 0.182 & 0.183 & 0.457 & 0.241 \\
\hline $3 \gamma /(2 \alpha \sqrt{ } 2 \beta)$ & \multicolumn{2}{|c|}{ No Region for some initial conditions $\left(x_{2 \mathrm{~m}}=0.8\right)$} \\
\hline
\end{tabular}

The boundary of the analytical safe basin is determined by Eq. (26).

$$
x_{2}=x_{2 \mathrm{~m}} \sqrt{1-\left(\frac{x_{1}}{x_{b}}\right)^{2}}, x_{1} \in\left[0, x_{b}\right]
$$

Secondly, the initial condition for rolling is selected by defining the bounded area $\left(A_{B}\right)$ as follows:

$$
A_{B}=\left\{\left(x_{1}, x_{2}\right): 0 \leq x_{1} \leq 1,0 \leq x_{2} \leq 1\right\}
$$

where $A_{B}$ is divided into the mesh of $58 \times 58$ points which are taken as the initial values for the solutions of the fourdimensional state space equations (6-9).

The equation system of rolling motion in random beam seas are numerically integrated by using the Euler Maruyama (EM) method [17] for different initial conditions as defined in Eq. (27) in order to investigate existence of a safe basin until either the roll angle exceeds a capsizing criterion reaching the point where the ship is assumed to capsize or the simulation end time (equal to 3000s in this study) is reached, in which it is assumed that the ship will remain upright $[15,19,23,26-28]$.

Tab. 12. The highest values of $x_{2 m}$ and $x_{b}$ for Sea state 2 with the initial values of $x_{1 s t}=0.1, k_{3}=0.2$ and $x_{a}=0.75$

\begin{tabular}{|c|c|c|c|c|}
\hline$x_{3 \mathrm{~m}}$ & $\begin{array}{c}x_{1 s t} \\
(\mathrm{rad})\end{array}$ & $\begin{array}{c}x_{2 \mathrm{~m}} \\
(\mathrm{rad} / \mathrm{s})\end{array}$ & $\begin{array}{c}x_{a} \\
(\mathrm{rad})\end{array}$ & $\begin{array}{c}x_{b} \\
(\mathrm{rad})\end{array}$ \\
\hline$\gamma /(3 \alpha \sqrt{2 \beta})$ & 0.082 & 0.346 & 0.394 & 0.404 \\
\hline$\gamma /(2 \alpha \sqrt{2 \beta})$ & 0.112 & 0.299 & 0.410 & 0.358 \\
\hline$\gamma /(\alpha \sqrt{2 \beta})$ & 0.190 & 0.176 & 0.458 & 0.232 \\
\hline $3 \gamma /(2 \alpha \sqrt{2 \beta})$ & \multicolumn{3}{|c|}{ No Region for some initial conditions $\left(x_{2 \mathrm{~m}}=0.7\right)$} \\
\hline
\end{tabular}

Tab. 13. The highest values of $x_{2 m}$ and $x_{b}$ for Sea state 3 with the initial values of $x_{1 s t}=0.1, k_{3}=0.2$ and $x_{a}=0.5$

\begin{tabular}{|c|c|c|c|c|}
\hline$x_{3 \mathrm{~m}}$ & $\begin{array}{c}x_{1 s t} \\
(\mathrm{rad})\end{array}$ & $\begin{array}{c}x_{2 \mathrm{~m}} \\
(\mathrm{rad} / \mathrm{s})\end{array}$ & $\begin{array}{c}x_{a} \\
(\mathrm{rad})\end{array}$ & $\begin{array}{c}x_{b} \\
(\mathrm{rad})\end{array}$ \\
\hline$\gamma /(3 \alpha \sqrt{2 \beta})$ & 0.100 & 0.327 & 0.393 & 0.387 \\
\hline$\gamma /(2 \alpha \sqrt{2 \beta})$ & 0.154 & 0.247 & 0.422 & 0.304 \\
\hline$\gamma /(\alpha \sqrt{2 \beta})$ & 0.216 & 0.138 & 0.473 & 0.192 \\
\hline $3 \gamma /(2 \alpha \sqrt{2 \beta})$ & \multicolumn{3}{|c|}{ No Region for some initial conditions $\left(x_{2 \mathrm{~m}}=0.8\right)$} \\
\hline
\end{tabular}

Tab. 14. The highest values of $x_{2 m}$ and $x_{b}$ for Sea state 3 with the initial values of $x_{1 s t}=0.1, k_{3}=0.2$ and $x_{a}=0.75$

\begin{tabular}{|c|c|c|c|c|}
\hline$x_{3 \mathrm{~m}}$ & $\begin{array}{c}x_{1 s t} \\
(\mathrm{rad})\end{array}$ & $\begin{array}{c}x_{2 \mathrm{~m}} \\
(\mathrm{rad} / \mathrm{s})\end{array}$ & $\begin{array}{c}x_{a} \\
(\mathrm{rad})\end{array}$ & $\begin{array}{c}x_{b} \\
(\mathrm{rad})\end{array}$ \\
\hline$\gamma /(3 \alpha \sqrt{ } 2 \beta)$ & 0.104 & 0.319 & 0.399 & 0.376 \\
\hline$\gamma /(2 \alpha \sqrt{ } 2 \beta)$ & 0.152 & 0.251 & 0.420 & 0.308 \\
\hline$\gamma /(\alpha \sqrt{ } 2 \beta)$ & 0.213 & 0.134 & 0.481 & 0.186 \\
\hline $3 \gamma /(2 \alpha \sqrt{ } 2 \beta)$ & \multicolumn{2}{|c|}{ No Region for some initial conditions $\left(x_{2 \mathrm{~m}}=0.8\right)$} \\
\hline
\end{tabular}


Safe basin is a set of initial conditions defined in the space of roll angle and roll angular phase [15, 19, 23, 26-28]. The safe initial conditions which are represented by white points do not cause the ship to capsize, whereas unsafe initial conditions leading to capsizing of the ship are represented by black points $[15,23,26-28]$.

The numerically and analytically obtained safe basins of the ship are shown in Figs. 2-4. In the figures the analytically determined boundaries are represented by a black line and the black points are the unsafe initial conditions. As can be seen from these figures, the number of the initial conditions causing the ship to capsize rapidly increases by the increment of sea state and also the analytically obtained safe basin appears smaller. It can be deduced from these figures that the boundary of safe basin obtained by Lyapunov's function is coherent with the numerical results, though more conservative.

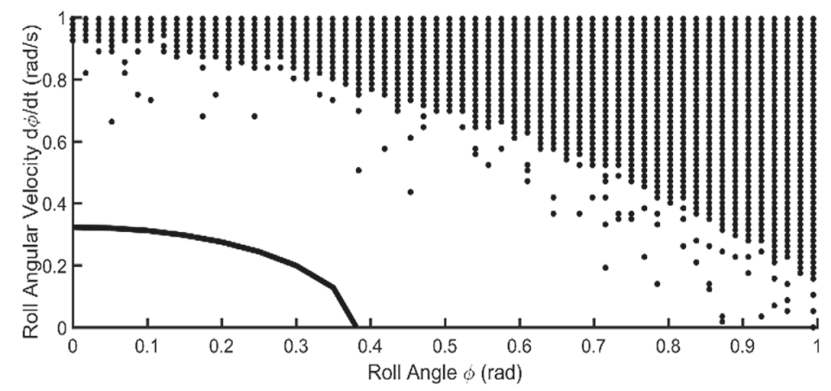

Fig. 2. Boundary of safe basin for Ship 1 and Sea state 1

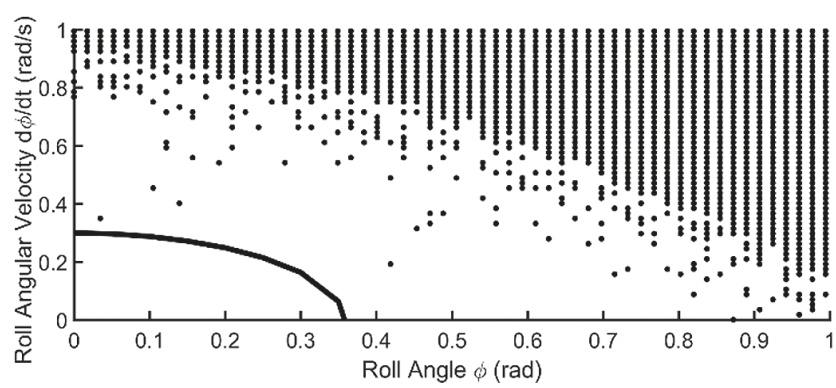

Fig. 3. Boundary of safe basin for Ship 1 and Sea state 2

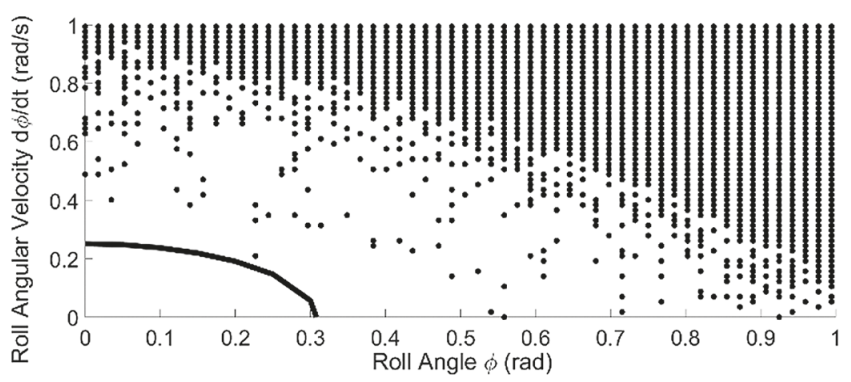

Fig. 4. Boundary of safe basin for Ship 1 and Sea state 3

\section{CONCLUSIONS}

In this study, the Lyapunov function is derived for the $4 \mathrm{D}$ system describing the roll motion in beam seas. The Lyapunov function is derived under the following assumptions:
- $x_{1 s t}$ is the intersection point of modified restoring arm and maximum value of external excitation arm.

- The roll angular velocity reaches its highest value $\left(x_{2 \mathrm{~m}}\right)$ when the roll angle is zero.

- The ship must have the half of the maximum roll angular velocity at the reference angle of heel determined by $x_{1 s t}$.

- The ship must have a residual arm of $h_{\text {res }}$ at the roll angle $x_{a}$. The magnitude of $h_{\text {res }}$ is determined by $x_{1 s t}$.

The Lyapunov function is derived by the maximum roll angular velocity $\left(x_{2 \mathrm{~m}}\right)$ and the width of safe basin $\left(x_{b}\right)$. Values of $x_{2 \mathrm{~m}}$ and $x_{b}$ are obtained from the solution of the equation system (20)-(25).

The necessary parameters of the equation system are: the restoring moment coefficients $\left(c_{1}, c_{3}\right)$, damping moment coefficients $\left(b_{44}, b_{44 q}\right)$, linear filter parameters $(\alpha, \beta, \gamma)$, the greatest value of the ratio of the external random wave excitation moment and the virtual mass moment of inertia $\left(x_{3 \mathrm{~m}}\right)$, as well as initial values of $x_{2}, x_{1 s t}, k_{3}^{*}$ and $x_{a}$. The way of selection of $x_{3 \mathrm{~m}}$ and initial values of $x_{2}, x_{1 s t}, k_{3}^{*}$ and $x_{a}$ is explained in Section 5.

With the existence and size of the safe basin obtained by Lyapunov function, it is possible to define whether the ship is stable or not in an examined sea state.

From the results of this study it can be concluded that the existence and size of the safe basin obtained by Lyapunov function can be used to derive an intact stability criterion to define a rule for the intact stability of ships.

\section{REFERENCES}

1. Balcer L.: Location of ship rolling axis, Polish Maritime Research, vol. 11, no. 1, pp. 3-7, 2004.

2. Biran, A. B.: Ship Hydrostatics and stability. ButterworthHeinemann, Oxford, 2003.

3. Belenky, V. L. and N. B. Sevastianov Stability and Safety of Ships: Risk of Capsizing ( $2^{\text {nd }}$ ed), SNAME, Jersey City, 2007.

4. Caldeira-Sariava, F.: The boundedness of solutions of a Leinard Equation arising in the theory of ship rolling. IMA J. Appl. Math, 36, pp. 126-139.

5. Chai W., Naess A. and Leira B. J.: Filter models for prediction of stochastic ship roll response, Probab. Eng. Mech., 41, pp. 104-114, 2015.

6. Chai W., Naess A., and Leira B. J.: Stochastic dynamic analysis and reliability of a vessel rolling in random beam seas, J. Ship Res., 59(2), pp. 113-131, 2015.

7. Chai W., Naess A. and Leira B. J.: Stochastic nonlinear ship rolling in random beam seas by the path integration method, Probab. Eng. Mech., 44, pp. 43-52, 2016.

8. Chai W., Naess A. and Leira B. J.: Long-term extreme response 
and reliability of a vessel rolling in random beam sea, J. Offshore Mech. and Arctic Eng., 140, 11601, pp. 1-9, 2018.

9. Dostal L. and Kreuzer E.: Probabilistic approach to large amplitude ship rolling in random seas, Proceedings of the Institution of Mechanical Engineers. Part C, Journal of Mechanical Engineering Science, 225, pp. 2464-2476, 2011.

10. Dostal L., Kreuzer E. and Namachchivaya: Non-standard stochastic averaging of large-amplitude ship rolling in random seas, Proceedings of the Royal Society A, 258, pp. 1-25, 2012.

11. Haddara M.: Modified approach for the application of Fokker - Plank equation to the nonlinear ship motions in random waves. Int. Shipbuilding Prog., 21(242), pp. 283-288, 1974.

12. Hutchison B. L.: The transverse plane motions of ships, SNAME Marine Tech., vol. 28, No. 2, pp. 55-72, 1991.

13. Jiang C., Troesch A. and Shaw, S.: Capsize criteria for ship models with Memory-Dependent Hydrodynamics and Random Excitation, Philos. Trans. R. Soc. Lond. Ser. A, 358(1771), pp. 1761-1791, 2000.

14. Jiang C.: Highly nonlinear rolling motion leading to capsize, University of Michigan, Ann Arbor, 1995.

15. Karakas S. C., Pesman E. and Ucer E.: Control design of fin roll stabilization in beam seas based on Lyapunov's direct method, Polish Maritime Research, No 2(73) Vol. 19, pp. 25-30, 2012.

16. Kushner H. J.: Stochastic stability and control, Academic Press, New York, 1967.

17. Kloden PE, Platen E: Numerical solution of stochastic differential equations. New York: Springer; 1995.

18. La Salle, J.P. and Lefschetz, S.: 1961. Stability by Lyapunov's Direct Method with Applications. Academic Press, New York.

19. Long, Z.Z., Lee, S.K., Kim, J.Y.: Estimation of survival probability for a ship in beam seas using the safe basin, Ocean Eng. Vol: 37, 418-424, 2010.

20. Moshchuk N., Ibrahim R. A. and Khasminskii R.: Response statics of ocean structures to nonlinear hydrodynamics loading Part I: Gaussian ocean waves, Jounal of Sound and Vibration, 184(4), pp. 681-701, 1995.

21. Odabasi, A.Y.: Stochastic stability of ships in following seas, Schiff \&Hafen, 3, pp. 223-226, 1979.

22. Ozkan, I.R.: Total (practical) Stability of ships, Ocean Eng., 8, pp. 551-598.

23. Rainey, R.C.T., Thompson, J.M.T.: The transient capsize diagram-a new method of quantifying stability analysis. J. Ship Res. 35 (1), pp. 58-92. 1991.

24. Roberts J.: A Stochastic Theory for Nonlinear Ship Rolling in Irregular Seas, J. Ship Res., 26(4), pp. 229-245, 1982.

25. Schurz H.: Verification of Lyapunov functions for the analysis of stochastic Lienard equations. J Sound Vib., 325: pp. 938-49, 2009.

26. Soliman, M.S., Thompson, J.M.T.: Transient and steady state analysis of capsize phenomena. Appl. Ocean Res. 13 (2), 82-92, 1991.

27. Thompson, J.M.T.: Loss of engineering integrity due to the erosion of absolute and transient basin boundaries, Proceedings of IUTAM Symposium on the Dynamics of Marine Vehicles and Structures in Waves, pp. 313-320, 1989.

28. Ucer E.: Examination of the trawlers in beam seas using safe basins, Ocean Eng., 38(17-18), pp. 1908-1915, 2011.

29. Yilmaz H.: Analyzing form parameters of fishing vessels point of view of practical stability criteria in preliminary design stage, Yildiz Technical University, Istanbul, 1998. 


\section{CONTACT WITH THE AUTHORS}

\section{Erdem Üçer}

e-mail:ucerer@itu.edu.tr

Istanbul Technical University

Faculty of Naval Architecture and Ocean Engineering

Ayazaga Campus, 34469 Istanbul

TURKEY 